\title{
Struggling for independence: A grounded theory study on convalescence of ICU survivors 12 months post ICU discharge
}

\author{
A.S. Ågård ${ }^{\mathrm{a}, *}$, I. Egerod ${ }^{\mathrm{b}}$, E. Tønnesen ${ }^{\mathrm{c}}, \mathrm{K}$. Lomborg ${ }^{\mathrm{d}}$ \\ a Department of Anesthesiology and Intensive Care, Aarhus University Hospital, Brendstrupgårdsvej 100, DK-8200 Aarhus N, \\ Denmark \\ b The University Hospitals Center for Nursing and Care Research, UCSF, Copenhagen University Hospital Rigshospitalet, \\ Department 9701, Blegdamsvej 9, DK-2100 Copenhagen O, Denmark \\ ' Department of Anesthesiology and Intensive Care, Aarhus University Hospital, Noerrebrogade 44, Building 21, DK-8000 Aarhus \\ $C$, Denmark \\ d School of Public Health, Department of Nursing Science, Aarhus University, Hoegh-Guldbergs Gade 6A, Building 1633, DK-8000 \\ Aarhus C, Denmark
}

\section{KEYWORDS}

Intensive care;

Critical care;

Rehabilitation;

Family;

Caregivers;

Spouses;

Convalescence;

Recovery

\begin{abstract}
Summary
Objectives: To explore and explain the challenges, concerns, and coping modalities in ICUsurvivors living with a partner or spouse during the first 12 months post ICU discharge.

Design: Qualitative, longitudinal grounded theory study.

Settings: Five ICUs in Denmark, four general, one neurosurgical.

Methods: Thirty-five interviews with patients and their partners at three and 12 months post ICU discharge plus two group interviews with patients only and two with partners only.

Findings: The ICU survivors struggled for independence and focussed chiefly on 'recovering physical strength', 'regaining functional capacity', and 'resuming domestic roles'. The first year of recovery evolved in three phases characterised by training, perseverance and continued hope for recovery. The ICU survivors did not seem to worry about traumatic experiences. Rather, their focus was on a wide range of other aspects of getting well.

Conclusion: The study offers new insight into post-ICU convalescence emphasising patients' motivation for training to recover. The findings may contribute to defining the best supportive measures and timing of rehabilitation interventions in ICU and post ICU that may help ICUsurvivors in their struggle for independence throughout recovery.

(c) 2012 Elsevier Ltd. All rights reserved.
\end{abstract}

\section{Introduction}

Critical illness and admission to the intensive care unit (ICU) radically affects patients and their close relatives during hospitalisation and after discharge. Internationally, the long-term consequences of critical illness and ICU admission have been identified as an important professional issue
* Corresponding author. Tel.: +45 2162 5484; fax: +45 78451215.

E-mail addresses: anne.agard@reher-langberg.dk (A.S. Ågård), ie@ucsf.dk (I. Egerod), elsetoen@rm.dk (E. Tønnesen), kl@sygeplejevid.au.dk (K. Lomborg). 
(Angus and Carlet, 2003; Blackwood et al., 2011; Chaboyer et al., 2005; Dowdy et al., 2005).

After critical illness, ICU survivors often suffer from disease-specific sequelae, general physical and psychosocial problems requiring considerable efforts to regain pre-ICU functional level (NHS, National Institute for Health and Clinical Excellence 2009; Broomhead and Brett, 2002; Desai et al., 2011; Oeyen et al., 2010). Further, a substantial portion of ICU survivors experience cognitive impairment affecting memory, attention, and executive function (Desai et al., 2011). Deficits in these central functional areas may have important consequences for activities of daily living, health-care management and social functioning (Hopkins and Jackson, 2009). The prevalence of posttraumatic stress disorder is reported to be 5-63\% (Jackson et al., 2007). For employed ICU survivors, the ability to return to work can be affected for months or indefinitely (Williams et al., 2010). The patients' health related quality of life has been reported to be generally lower than that of the background population in the first year after discharge (Chaboyer and Elliott, 2000; Dowdy et al., 2005), perhaps even longer (Ulvik et al., 2008).

The patients' close relatives are also affected by the adverse consequences of critical illness and its aftermath (Ågård and Harder, 2007; Linnarsson et al., 2010). As informal post-ICU caregivers, they may experience considerable lifestyle disruption and strain (Choi et al., 2011; Van Pelt et al., 2007).

In summary, recovery can be a strenuous time for both ICU survivors and their close relatives. Little is known, however, about the everyday concerns of ICU survivors and their cohabiting partners and the coping modalities employed to meet the challenges facing the couples. Better insight into these sparsely researched areas could provide health care staff with a stronger basis for preparing ICU survivors and their close relatives for post-ICU recovery.

The study is part of a larger project exploring the situation of ICU survivors and their cohabiting spouse or partner during the first 12 months following ICU discharge. The present study offers insight into some of the challenges facing ICU survivors and focusses chiefly on their concerns and coping modalities in the 12-months post ICU discharge. The next part of the project concerns the role of the partners during post ICU recovery and is in process. In the final part of the project we will address the concrete trajectories of patients and their partners.

\section{Aim}

The aim of the study was to explore the challenges facing ICU survivors with a cohabiting spouse or partner and explain patients' concerns and coping modalities during the first 12 months post ICU discharge.

\section{Methods and material}

\section{Design and setting}

The study was a qualitative, explorative, longitudinal study based on classic grounded theory (GT) methodology (Glaser, 1978; Glaser and Strauss, 1967) with a realist epistemological perspective (Lomborg and Kirkevold, 2003). Participants were from five Danish ICUs: four general ICUs (level 2 and 3) and one neurosurgical ICU (level 2) with 7-13 beds. The ICUs were situated at three university hospitals and one regional hospital. In 2009, the number of patients admitted to the five ICUs was 492-926 ranging from the smallest to the largest unit.

\section{Participants and recruitment}

Over a ten-month period, participants were recruited as a convenience sample from five ICUs. The heterogeneity of the ICU-population both pre and post ICU represents a challenge in ICU research (Herridge, 2007; Chaboyer and Elliott, 2000). Furthermore, when including relatives in post-ICU research, the type of relation is not always specified, although important differences have been found in the way the burden is experienced by the patient's partner, children, friends, parents, or other relatives (Foster and Chaboyer, 2003). To avoid some of the problems of heterogeneity, our inclusion criteria were quite narrow: (1) ICU survivors aged 25-70 years (people of working age), (2) intubation $>96$ hours (to target the more severely ill patients) (Douglas and Daly, 2003), (3) patients with a cohabiting partner (potential primary caregiver after discharge), and (4) ability to communicate adequately in Danish.

To minimise the impact of prior illness on post-ICU recovery, we excluded patients with conditions that might have severely affected the patient's daily life prior to ICU admission (Orwelius et al., 2010). In addition to patients with major heart, lung, (e.g. Chronic obstructive pulmonary disease), or neurological disease, we also excluded patients with conditions such as depression, brain damage, schizophrenia, cancer, a recent history of drug/alcohol abuse prior to admission, or after attempted suicide. Finally, the patient was excluded if a pre-admission health status was missing in the hospital chart. Based on information from hospital charts, each potential participant was assessed for eligibility on a pragmatic basis by the first author.

\section{Ethical considerations}

After ethical and legal approval from the National Board of Health (J.nr. 7-604-04-2/158/EHE) and the Danish Data Protection Agency (J.nr. 2009-41-3022), we identified potential participants retrospectively from ward-based ICU databases and subsequent examination of hospital charts in five different ICUs. After careful selection, a total of 36 patients were identified consecutively by the first author. Before the initial contact we checked the hospital registers to make sure potential participants were alive. Subsequently, the patients and their partners were contacted by regular mail 10 weeks after ICU discharge and invited to participate in the study. Prospective participants were informed about the study verbally and in writing, the right to withdraw at any time, confidentiality and anonymity and asked to sign a letter of informed consent. A flow chart of the enrolment of patients and partners is provided in Fig. 1. 


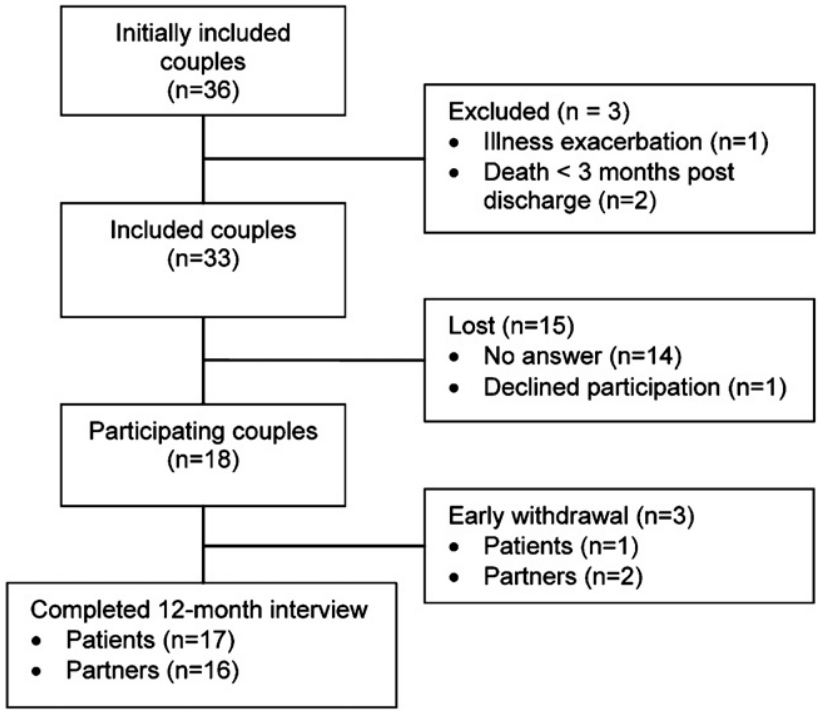

Figure 1 Patient and caregiver enrollment.

\section{Data collection and analysis}

Data consisted of dyad interviews with 18 patients and their partner at three $(n=18+18)$ and $12(n=17+16)$ months post ICU discharge. One couple and one partner withdrew from the study before the 12-month interview. The interviews took place in the couples' home or in a quiet room at the hospital. In addition to dyad interviews, we did two focus group interviews with patients only $(n=3$ and $n=7)$ and two with partners only ( $n=2$ and $n=7)$, as there could be issues that the couples did not want to discuss openly (Svedlund and Axelsson, 2000; Hupcey, 1999). At the time of the group interviews some participants had been discharged 12-14 months ago, while others were discharged 3-4 months ago providing a wide range of patient experiences from different points in time after discharge. The group interviews were conducted somewhere between the three and 12-month interview rounds in meeting facilities at one of the hospitals.

The procedures of data collection, coding, memo writing, and analysis were performed concurrently using the constant comparative method central to GT methodology (Glaser and Strauss, 1967). During the initial three-month interviews, open coding was conducted and the core category "Struggling for independence" applied by the ICUsurvivors to solve their main concerns was identified. As the analysis progressed, coding became more selective to identify further properties and dimensions of the emerging theory. The analytic perspective gradually evolved from a focus on particulars to a more general and conceptual level supported by written memos from the entire study period on the theoretical relationships between codes, categories, and concepts. As we focussed on recovery during the first 12 months after ICU discharge, we had to remain open to new insights throughout the entire process of data collection and analysis (Glaser, 1978). In the interviews participants elaborated on aspects from the time after ICU discharge giving examples from the entire recovery period. Writing memos helped us stay theoretically sensitive throughout the process of data collection and analysis as we were able to track the emergence of provisional ideas and compare those with later findings averting premature analytical conceptions (Glaser and Strauss, 1967). During the 12-month interviews, we coded both selectively and theoretically, while we further tested our ideas and looked for changes in concerns over time, while gradually saturating our substantive grounded theory.

The semi-structured interview guide was refined several times, as the interviews became more focussed in accordance with the principle of theoretical sampling and reflecting the emergence of our theory (Glaser and Strauss, 1967).

The 60-90minute interviews were audio-taped and transcribed verbatim. The text version of the interviews provided the primary basis for the systematic coding and analysis. The first author conducted all interviews over a 19-month period in 2009-2010. The first and last authors contributed to the data analysis, which was supported by use of software package NVivo8.

\section{Findings}

\section{Struggling for independence}

During the first year of convalescence, the patients struggled for independence. The struggle evolved in three modalities: recovering physical strength, regaining functional capacity, and resuming domestic roles. These modalities followed a trajectory of three phases all characterised by training, perseverance, and continued hope for recovery (Table 2). Before we elaborate on the phases, in the following we present their context.

\section{The context of post-ICU recovery}

The Danish welfare system provides extensive financial and health care related security to Danish citizens. For a description of the Danish health care system, we refer to an official Danish website (The Ministry of the Interior and Health). Patient characteristics are provided in Table 1 to illustrate the context of everyday post-ICU recovery.

Patients were aged $35-70$ years; 11 were men, 7 women. The ICU survivors, who were all generally in good health prior to critical illness, reported a wide range of complications in the first year after ICU discharge. The majority had experienced weight loss (5-25 kilos), fatigue, and loss of appetite. Two had persistent residual symptoms after critical illness polyneuropathy affecting their fine motor skills. Another patient had difficulty swallowing as a result of intubation. Depending on the ICU admission diagnosis, some of the patients also had various injuries causing reduced physical function (e.g. bone fractures) or impaired eyesight or hearing. One patient was initially quadriplegic, but partially recovered the use of his arms and legs.

Most of the patients with primary brain injuries or cerebral problems secondary to other conditions, e.g. hypoxia or septicaemia, reported cognitive symptoms such as reduced memory, concentration, or planning ability. Some patients with no known cerebral damage reported confusion or lack of initiative and reduced concentration or irritability in the initial period after ICU discharge and attributed these symptoms to their weak physical constitution in general. Two 
Table 1 Patient characteristics in ICU and at 12 months post ICU discharge.

\begin{tabular}{|c|c|c|c|c|c|c|c|c|c|c|c|c|c|}
\hline & Age & Sex & Type & $\begin{array}{l}\text { LOS } \\
\text { ICU }\end{array}$ & $\begin{array}{l}\text { LoS } \\
\text { Hosp. }\end{array}$ & $\begin{array}{l}\text { LoS } \\
\text { Rehab. } \\
\text { facility }\end{array}$ & $\begin{array}{l}\text { Th. } \\
\text { physical }\end{array}$ & $\begin{array}{l}\text { Th. } \\
\text { neuropsych. }\end{array}$ & $\begin{array}{l}\text { Th. } \\
\text { private } \\
\text { phys. }\end{array}$ & $\begin{array}{l}\text { Sick } \\
\text { leave F-T }\end{array}$ & $\begin{array}{l}\text { Sick } \\
\text { leave P-T }\end{array}$ & $\begin{array}{l}\text { Pre- } \\
\text { employment } \\
\text { rate }\end{array}$ & $\begin{array}{l}\text { Employment } \\
\text { rate at } 12 \\
\text { months }\end{array}$ \\
\hline 1 & 35 & M & Trauma & 11 & 12 & - & 12 & - & - & 353 & 0 & 37 & 20 \\
\hline 4 & 40 & $\mathrm{~F}$ & Gastric & 67 & 8 & 106 & 20 & 13 & - & 251 & 0 & 37 & 16 \\
\hline 5 & 40 & M & Neuro & 10 & 6 & 21 & - & - & - & Ue & $\mathrm{Ue}$ & Ue & Ue \\
\hline 6 & 45 & $\mathrm{~F}$ & Pulmonary & 73 & 47 & 119 & 28 & - & - & 92 & 107 & 37 & 12 \\
\hline 10 & 58 & $\mathrm{~F}$ & Pulmonary & 10 & 37 & - & 8 & - & - & 90 & 0 & 15 & 15 \\
\hline 11 & 60 & M & Neuro & 12 & 6 & 57 & 3 & 18 & 8 & 302 & 0 & 37 & 30 \\
\hline 12 & 63 & M & Trauma & 11 & 42 & - & 34 & - & - & 323 & 0 & 37 & 0 \\
\hline 13 & 64 & $M$ & Trauma & 51 & 7 & 174 & 25 & - & - & Ret & Ret & Ret & Ret \\
\hline 14 & 67 & M & Cardiac & 74 & 7 & 27 & 12 & - & - & Ret & Ret & Ret & Ret \\
\hline 15 & 68 & M & Cardiac & 7 & 16 & - & 8 & - & 28 & Ret & Ret & Ret & Ret \\
\hline 16 & 68 & M & Trauma & 21 & 3 & 55 & 8 & - & - & Ret & Ret & Ret & Ret \\
\hline
\end{tabular}


ICU survivors recalled unpleasant hallucinations or unreal experiences, while two others remembered pleasant hallucinations. After a year none of the patients felt this was a problem.

Due to complications related to critical illness and hospitalisation, the patients still needed care upon their return home, leaving a substantial responsibility with the partner to provide the care needed, and most of the patients reported experiencing a renewed feeling of connectedness with their partner and family. Besides their everyday household activities and general support, the partners assisted with, e.g. meals, medications, personal hygiene, planning, social activities, and transportation to the hospital or general practitioner. After 12 months, three out of 11 patients had resumed their pre-ICU employment rate.

For the ICU survivors the 12-month post-ICU period of recovery was generally characterised by hope for further recovery. Some of the patients experienced progress or even recovery in most areas, while others still struggled with residual complications 12 months post-ICU discharge.

\section{Recovering physical strength}

Essential to the patients' struggle for independence was their effort to re-establish premorbid physical strength, which required months of training partly in hospital or in a rehabilitation facility and partly in community-based programmes (Table 1). Most of the participants had lost weight and muscular strength during hospitalisation. The resulting physical weakness required a lot of effort to regain normal physical strength for everyday activities such as getting out of bed, getting up from a chair, showering, dressing, climbing stairs, and moving about in the house or outside. This is summarised by an elderly male describing his situation prior to transfer to rehabilitation:

"Then I had to try to get up with a walker and I just couldn't. I couldn't even hold my head. I wasn't able to do anything."

(ID no. 14, male, 67 years)

Later, exercise was directed towards recovering physical strength for short walks outside, shopping, gardening, etc. gradually expanding the range of activities. Even after substantial training for a year, not all participants had returned to their pre-ICU level of physical strength and activity. An elderly male explained during the 12-month interview:

"The most difficult bit was ... I felt it took forever before I regained my strength. I just deposited my physical strength at the hospital and I still feel it. I mean, I don't feel I am up to my usual strength yet. I need an afternoon nap, sometimes two. I feel that I need more strength to open the lid of a jar of jam. I was actually quite strong before I got sick."

(ID no. 15, male, 68 years)

During the first months after ICU discharge, the training activities combined with frequent hospital appointments often entailed a tight schedule for the patients leaving little energy for other activities such as interaction with friends and family during the week.

\section{Regaining functional capacity}

While gradually recovering their physical strength, the patients simultaneously tried to regain functional capacity allowing them to perform pre-ICU everyday activities. As a patient stated at the 12 month interview: "Happiness is doing things yourself" (ID no. 9).

Regaining functional capacity involved developing new ways of performing all sorts of activities to compensate for possible physical or cognitive shortcomings whether temporary or permanent. If the patients were not fully capable of performing a specific activity, they would try again later or find a different way of performing the activity, or the partner would assist them to complete the activity or take over. To illustrate the many accounts of this type of resourcefulness, a patient explained during the 12-month interview:

"In the beginning when I came home and wanted to go upstairs, I sat on my behind and went up and down the stairs. It took a while before I could get around."

(ID no. 6, female, 45 years)

Patients with cognitive impairment had to relearn performing basic activities such as dressing, personal hygiene, keeping track of things, cooking, cleaning, etc. Even if the cognitive deficits had a major impact on their everyday capabilities, most often the patients failed to report their difficulties, suggesting perhaps inability to acknowledge, accept, or comprehend the gravity of their situation. If the patients lacked this insight, the partner would recall situations where they had supported the patient in activities requiring these skills.

Typically, the partners were involved in situations where the patient's functional capacity was inadequate, such as actively helping with a specific activity or by rearranging things in and around the house.

As the patients gradually recovered basic functions during recovery, their goals shifted towards practicing functions at a more complex and complicated level such as planning, organising, shopping, driving a car again, or perhaps returning to work. Regaining their functional capacity, the ICU survivors were pleased as they gradually became independent of the health care system or the social system.

\section{Resuming domestic roles}

Resuming domestic roles was central to the patients' struggle for independence. After their illness, the patients were weak and unable to worry about the extent of help from their partners. Later, they became increasingly aware of their changed roles in their relationship with their partner. During recovery the patients gradually attempted to reduce their dependency and the burden on their spouse. As a patient said at the 12-month interview:

"I probably went too far. I mean, I was at home and tried to arrange that my husband didn't need to come home and do things. But then I was tired and couldn't handle it anyway."

(ID no. 2, female, 40 years) 
Table 2 The three phases in patients' coping modalities during the first year of post-ICU recovery.

\begin{tabular}{|c|c|c|c|}
\hline & Feeling one's way & Getting a grip & Maintaining and refining \\
\hline Recovering physical strength & $\begin{array}{l}\text { Training to recover basic } \\
\text { physical strength for } \\
\text { performing basic everyday } \\
\text { indoor activities with little } \\
\text { idea of the effort needed to } \\
\text { recover premorbid physical } \\
\text { strength }\end{array}$ & $\begin{array}{l}\text { Training to recover } \\
\text { additional physical strength } \\
\text { for performing more } \\
\text { physically demanding tasks } \\
\text { in and around the home } \\
\text { while gradually realising the } \\
\text { extent of the physical } \\
\text { training needed to recover }\end{array}$ & $\begin{array}{l}\text { Continued efforts to recover } \\
\text { further physical strength or } \\
\text { maintain their level of } \\
\text { strength while gradually } \\
\text { expanding the range of the } \\
\text { patients' physical activities }\end{array}$ \\
\hline Regaining functional capacity & $\begin{array}{l}\text { Trying to perform basic } \\
\text { everyday activities } \\
\text { alternating with periods of } \\
\text { rest or sleep }\end{array}$ & $\begin{array}{l}\text { Gradually developing new } \\
\text { ways of performing all sorts } \\
\text { of activities to compensate } \\
\text { for temporary or permanent } \\
\text { disabilities }\end{array}$ & $\begin{array}{l}\text { Practicing functions at a } \\
\text { progressively more complex } \\
\text { and complicated level both } \\
\text { physically and } \\
\text { psychosocially }\end{array}$ \\
\hline Resuming domestic roles & $\begin{array}{l}\text { Being relatively dependent } \\
\text { on help from the partner } \\
\text { and accepting the help } \\
\text { provided often without } \\
\text { considering the extent of } \\
\text { the help }\end{array}$ & $\begin{array}{l}\text { Testing the range of their } \\
\text { functional capability and } \\
\text { still leaning to some extent } \\
\text { on assistance from the } \\
\text { partner while being } \\
\text { increasingly aware of the } \\
\text { help provided }\end{array}$ & $\begin{array}{l}\text { Gradually becoming } \\
\text { independent of assistance } \\
\text { while actively freeing } \\
\text { themselves more and more } \\
\text { of their partner's help and } \\
\text { expanding their territory in } \\
\text { the relationship }\end{array}$ \\
\hline
\end{tabular}

The patients had an active role in minimising their partner's help. Generally, the patients felt their partner was there for them in a helpful way. On the other hand, as they gradually recovered, several patients mentioned incidents where they had actively confronted their partner telling them to stop their help or advice. The patients were annoyed by the partner's interference, when they felt capable of performing a certain activity, big or small. They gradually expanded their territory in the interactions with their partner. At the 12-month interview one patient said:

"But this is also something we have had to deal with, from me being the one that was protected in all situations in the best possible way, to my husband who had a hard time accepting that now I wanted to do things myself. I couldn't ... I felt overprotected; I was able to unpack my own suitcase. We went on and on about this. It was simply that our roles had to return to normal, because I was almost myself again."

(ID no. 9, female, 55 years)

When asked about the characteristics of this evolving process, the participants described it as an intuitive trialand-error approach continuously testing their capabilities while leaning to some extent on assistance from their partner. The patients wanted to avoid being a burden to others: "It sucks knowing that I am a burden" (Patient ID no. 3 at group interview). This affected recovery in various ways as illustrated in the following quote:

"You know what, I don't want to go home and have my wife help me get to bed and help me go to the bathroom - and if I fall - I just don't want to be a burden to her. That's it! When I can walk again it will be different."

(ID no. 13, male, 64 years, at three months)

\section{Three phases}

The first year of recovery evolved in three phases all characterized by training, perseverance, and continued hope of recovery. A summarising description of the phases is provided in Table 2.

Training, perseverance, and continued hope for recovery were the vehicles that moved the process of struggling for independence forward taking the patient from one phase to another. Physical strength was a prerequisite for the patients' effort to regain functional capacity, and with increased functioning the patients resumed their domestic roles. Improving any aspect of functional level increased the patients' momentum to keep on struggling for independence. Through statements like: "Keep going", "Be patient", "Hang in there" (physical training), or "Don't give up" they all emphasised the need to continue even if things were tough. The participants provided rich descriptions of the feeling of reward when progress was made. In general, whether they had more or fewer complications, the patients all expressed a strong motivation and resourcefulness to regain the best possible functional level physically as well as psychosocially, and 12 months post ICU there was still hope for further recovery. The patients acknowledged the importance of their partners' efforts moving the process of recovery forward when they themselves lost their resolve.

\section{Discussion}

The primary finding of the study was that the study patients did not seem to worry about traumatic experiences or psychological complications. Instead, their focus was on overcoming everyday physical and functional challenges, and the patients showed resourcefulness. 
Studies on psychosocial complications after critical illness, e.g. posttraumatic stress, depression, or anxiety, have shown that these conditions are common amongst ICUsurvivors (Oeyen et al., 2010; Davydow et al., 2008; Desai et al., 2011). Hence, we were surprised to learn that the ICU survivors in our study did not seem to worry about traumatic experiences or memories of being in intensive care or from the incident that initially caused their illness. Instead, they focussed on other aspects of recovery that are common amongst non-intensive care patients. For ethical reasons, we were unable to ask non-participants about their reasons for declining, and consequently we can only speculate about this. The patients were invited to participate in the study 10 weeks post ICU-discharge when the prospects for recovery were still unclear to most of them. In the study group, however, both ICU survivors struggling with major and minor complications were represented, suggesting that they did not influence the decision to participate.

There may be various reasons why the patients appeared less psychologically traumatised than earlier studies indicate. First, the patients did not seem to have symptoms of trauma. At three and 12 months, most of the patients had no recollection of their time in ICU. They were generally grateful to have survived and appreciated the lifesaving treatment and care provided by professionals who they also failed to recall. The patients did not look back to re-live their ICU experiences; they looked to the future and concentrated on regaining the abilities they had lost. This is in conflict with ICU literature describing the trauma of intensive care but might to some extent be explained by looking at the context of our study. The participants were recruited from ICUs representing a new paradigm in intensive care encouraging less sedation, shorter duration of mechanical ventilation, early mobilisation, awareness of delirium, and more family collaboration (Egerod, 2009). Consequently, less negative patient experiences could be reflections of improvements in intensive care.

There are indications that the focus on physical recovery precedes the focus on psychological recovery. Therefore, if the follow-up period had extended to more than 12 months, a tendency towards more emotional problems might be found (Oeyen et al., 2010). Therefore, we encourage followup studies beyond 18 or 24 months post ICU discharge.

Generally, the patients did not feel their experiences had been traumatising. On the other hand, a few patients had problems with concentration or increased irritability, which may be diffuse symptoms of depression or posttraumatic stress disorder (American Psychiatric Association (APA), 2006). As these conditions often associated with post-ICU recovery can only be properly detected through systematic screening, we were unable to establish if the diffuse symptoms mentioned could be indicators of psychiatric conditions.

Another explanation could be that the patients in our study all had their spouses by their side supporting them in hospital and at home. Studies show that close relatives help patients understand what happened in ICU and help them come to terms with the illness experience as a part of their recovery (Egerod et al., 2011). The patients' family has been described as a lifeline for the patient in ICU (Bergbom and Askwall, 2000) as well as after discharge, and their role in
post-ICU recovery is an important area for future research (Paul and Rattray, 2008).

The study participants were generally in good health before their critical illness and therefore had a robust starting point for recovery. This could be another reason why they did not seem traumatised. Orwelius and colleagues found, that previously healthy ICU patients had a health-related quality of life (HQOL) after ICU almost identical to that of a group of non-hospitalised citizens that were not entirely healthy, but had no history of critical illness or admission to ICU (Orwelius et al., 2010). The authors reported that ICUrelated factors such as APACHE II score, length of stay in ICU, and ventilator time were not associated with HQOL, whereas pre-existing disease prior to ICU admission accounted for most of the reduction in HQOL in ICU survivors (ibid). Consequently, future studies of post-ICU recovery should look at pre-existing disease.

The study patients suffered a range of physical and psychosocial sequelae with varying impact on their everyday lives. The reported complications were consistent with those described in the literature (Desai et al., 2011). The patients' main concern across the reported range of complications was to overcome the obstacles on their road to recovery. Their main object was similar to the goals of recovery for patients suffering from spinal cord injuries (Angel, 2010) or other less life-threatening illnesses (Sigurgeirsdottir and Halldorsdottir, 2008). Elements of the three phases of post-ICU recovery were found in recovery after spinal cord injury (Angel, 2009). The ICU recovery phases were also similar to aspects of theories of crisis and coping in general (Cullberg, 1993), indicating universal phenomena of recovery.

The quality of life of some of the study participants was at times significantly reduced, which is not surprising considering the gravity of their illness and the efforts needed to recover. Even so, patients also reported experiencing new qualities in life such as renewed feelings of connectedness with their partner and family and gratitude for being alive that seemed to fundamentally influence their recovery. We did not systematically evaluate quality of life, but we were encouraged to learn that some patients also had positive experiences after critical illness, even if they suffered from physical or cognitive sequelae. These aspects of post-ICU recovery would probably have remained invisible in conventional quality of life studies.

When researchers in the past have discussed the difficulties of ICU survivors, they may have neglected to describe less spectacular reactions to intensive care, thus leaving a gap in the current body of knowledge. To paint a more complete picture of ICU-recovery, we suggest to further integrate more general aspects of rehabilitation shared with non-ICU patients and to also describe possible positive perspectives, as in a recent study (Samuelson, 2011), without neglecting the challenges facing patients and their families in ICU and after discharge.

Our study shows, that in spite of various problems after critical illness, patients and their partners could be resourceful. Similar results were found in a group of patients with spinal cord injuries (Angel, 2010). As there is still some uncertainty as to the effects of existing post-ICU followup programmes (Cuthbertson et al., 2009) involving the resources and experiences of ex-patients and relatives in 
community-based support groups could be a promising supplement to existing hospital based follow-up programmes (Peskett and Gibb, 2009).

In GT-methodology, the criteria for critically appraising a theory are whether it 'fits', 'works', is 'relevant' and 'modifiable' (Glaser, 1978; Lomborg and Kirkevold, 2003). As we carefully adhered to the analytic strategies of the methodology, we believe the theory fits the data from which it evolved offering a coherent theory on the patients' main concern and coping modalities employed to overcome postICU challenges. In spite of narrow criteria for inclusion, the characteristics of our study participants varied considerably. Even so, we found concurrent patterns in the patients' main concerns and behaviour increasing the scope of the theory and adding to the workability of the theory to explain, predict, and interpret what is happening in post-ICU recovery. We believe the theory is relevant to health care providers striving to support ICU survivors in the first year of recovery. As it also seems to imply some universal elements of recovery, we believe it also could be modified for groups of non-intensive care patients.

Long-term ICU rehabilitation is a growing field of interest to health care professionals and researchers. To enhance our current understanding of post-ICU recovery, we suggest seeking further inspiration and perspectives from other medical specialties including illnesses that are less life-threatening and in areas with more experience in rehabilitation, e.g. occupational therapy or physiotherapy. Increased awareness amongst ICU-staff of post-ICU patients' motivation for training could contribute to promoting early mobilisation in ICU. Besides reducing patients' physical impairment, early mobilisation could also contribute to instilling hope and empowering patients in the early process of recovery.

As more patients survive critical illness and face the challenges of recovery, survivorship could be the defining challenge in critical care encouraging new approaches to treatment and care (Iwashyna, 2010). We suggest that qualitative research approaches are applied to gain further insight into the challenges facing patients in ICU and after discharge. Furthermore, in line with the principles of familycentred care in ICU (Davidson et al., 2007), future research on the role of patients' close relatives after ICU discharge is an important issue that could yield new insights providing a more holistic basis for the continued efforts of health care professionals and researchers to improve treatment and care.

\section{Conclusion}

In this grounded theory study of recovery 12 months post ICU, the patients struggled for independence and focussed chiefly on exercising to recover physical strength, regaining functional capacity and resuming domestic roles. The first year of recovery evolved in three phases characterised by training, perseverance, and continued hope of recovery. The patients in our study did not verbalise traumatic experiences or recollections from intensive care. Instead, their focus was on recovery similar to that of non-intensive care patients.

The findings from this qualitative study offer new insights into the trajectories of ICU survivors and their concerns after critical illness complementing our current understanding of post-ICU recovery. The findings may contribute to defining the best supportive measures and timing for post-ICU rehabilitation that may help ICU survivors in their struggle for independence throughout recovery.

\section{Conflict of interest statement}

The authors and the funders have no financial or personal relationships that could inappropriately influence this work.

\section{Acknowledgements}

We are grateful to the participating patients, spouses, and partners for sharing their experiences of life after ICU. Also, we thank the ICU nurses and administrative staff who facilitated the collection of data. Thanks also to Janet Mikkelsen, Department of Public Health, Aarhus University for help in editing the manuscript language. The study was supported by grants from The Novo Nordisk Foundation, The Health Insurance Foundation, The Danish Nurses' Organisation, Aarhus University Hospital, The Aase and Ejnar Danielsen Foundation, The Lundbeck Foundation and The Central Jutland Region.

Contributors: ASÅ, KL, ET, IE contributed in the conception and design of the study; $A S \AA \AA, K L$ in drafting the manuscript; $A S \AA, K L, E T, I E$ in improving the manuscript; the final approval was made by ASÅ.

\section{References}

Ågård AS, Harder I. Relatives' experiences in intensive care-finding a place in a world of uncertainty. Intensive Crit Care Nurs 2007;23(3):170-7.

APA practice guidelines for the treatment of psychiatric disorders: comprehensive guidelines and guideline watches; practice guideline for the treatment of patients with acute stress disorder and posttraumatic stress disorder. American Psychiatric Publishing, Inc.; 2006. Available from: http://psychiatryonline.org/ content . aspx? bookid $=28$ \& sectionid $=1670530 \# 52640$ [Accessed 01/05/2012].

Angel S. Vulnerable, but strong: the spinal cord-injured patient during rehabilitation. Int $\mathrm{J}$ Qual Stud Health Well-being 2010;5(October (3)), 10.3402/qhw.v5i3.5145.

Angel S. Getting on with life following a spinal cord injury: regaining meaning through six phases. Int J Qual Stud Health Well-being 2009;4(1):39-50.

Angus DC, Carlet J, editors. Surviving intensive care. Heidelberg: Springer-Verlag Berlin; 2003.

Bergbom I, Askwall A. The nearest and dearest: a lifeline for ICU patients. Intensive Crit Care Nurs 2000;16(6):384-95, 12//;

Blackwood B, Albarran JW, Latour JM. Research priorities of adult intensive care nurses in 20 European countries: a Delphi study. J Adv Nurs 2011;67(March (3)):550-62.

Broomhead LR, Brett SJ. Clinical review: intensive care follow-up-what has it told us? Crit Care 2002;6(October (5)):411-7.

Chaboyer W, James H, Kendall M. Transitional care after the intensive care unit: current trends and future directions. Crit Care Nurse 2005;25(June (3)):16.

Chaboyer W, Elliott D. Health-related quality of life of ICU survivors: review of the literature. Intensive Crit Care Nurs 2000;16(April (2)):88-97. 
Choi J, Donahoe MP, Zullo TG, Hoffman LA. Caregivers of the chronically critically ill after discharge from the intensive care unit: six months' experience. Am J Crit Care 2011;20(January (1)):12-22.

Cullberg J. Krise og udvikling: en psykoanalytisk og socialpsykiatrisk studie [Crisis and development: a psychoanalytical and social psychiatric study]. 4. udgave ed. Kbh.: Hans Reitzel; 1993.

Cuthbertson BH, Rattray J, Campbell MK, Gager M, Roughton S, Smith A, et al. The PRaCTICaL study of nurse led, intensive care follow-up programmes for improving long term outcomes from critical illness: a pragmatic randomised controlled trial. BMJ 2009;339(October):b3723.

Davidson JE, Powers K, Hedayat KM, Tieszen M, Kon AA, Shepard $E$, et al. Clinical practice guidelines for support of the family in the patient-centered intensive care unit: American college of critical care medicine task force 2004-2005. Crit Care Med 2007;35(2):605-22.

Davydow DS, Gifford JM, Desai SV, Needham DM, Bienvenu OJ. Posttraumatic stress disorder in general intensive care unit survivors: a systematic review. Gen Hosp Psychiatry 2008;30(September-October (5)):421-34.

Desai SV, Law TJ, Needham DM. Long-term complications of critical care. Crit Care Med 2011;39(February (2)):371-9.

Douglas SL, Daly BJ. Caregivers of long-term ventilator patients: physical and psychological outcomes. Chest 2003;123(April (4)):1073-81.

Dowdy DW, Eid MP, Sedrakyan A, Mendez-Tellez PA, Pronovost PJ, Herridge MS, et al. Quality of life in adult survivors of critical illness: a systematic review of the literature. Intensive Care Med 2005;31 (May (5)):611-20.

Egerod I. Cultural changes in ICU sedation management. Qual Health Res 2009;19(May (5)):687-96.

Egerod I, Christensen D, Schwartz-Nielsen KH, Ågård AS. Constructing the illness narrative: a grounded theory exploring patients' and relatives' use of intensive care diaries. Crit Care Med 2011;39(May (8)):1922-8.

Foster M, Chaboyer W. Family carers of ICU survivors: a survey of the burden they experience. Scand J Caring Sci 2003;17(3):205-14.

Glaser BG. Theoretical sensitivity. Advances in the methodology of grounded theory. Mill Valley, CA: Sociology Press; 1978.

Glaser BG, Strauss AL. The discovery of grounded theory: strategies for qualitative research. Hawthorne, New York: Aldine de Gruyter; 1967.

Herridge MS. Long-term outcomes after critical illness: past, present, future. Curr Opin Crit Care 2007;13(October (5)):473-5.

Hopkins RO, Jackson JC. Short- and long-term cognitive outcomes in intensive care unit survivors. Clin Chest Med 2009;30(March (1)): 143-53, ix.

Hupcey JE. Looking out for the patient and ourselves-the process of family integration into the ICU. J Clin Nurs 1999;8(3):253-62.

Iwashyna TJ. Survivorship will be the defining challenge of critical care in the 21st century. Ann Intern Med 2010;153(August (3)):204-5.
Jackson JC, Hart RP, Gordon SM, Hopkins RO, Girard TD, Ely EW. Post-traumatic stress disorder and post-traumatic stress symptoms following critical illness in medical intensive care unit patients: assessing the magnitude of the problem. Crit Care 2007;11(1):R27.

Linnarsson JR, Bubini J, Perseius KI. Review: a meta-synthesis of qualitative research into needs and experiences of significant others to critically ill or injured patients. J Clin Nurs 2010;19(21-22):3102-11.

Lomborg K, Kirkevold $M$. Truth and validity in grounded theorya reconsidered realist interpretation of the criteria: fit, work, relevance and modifiability. Nurs Philos 2003;4:189-200.

NHS, National Institute for health and Clinical Excellence: rehabilitation after critical illness; 2009. Available from: www.nice.org.uk/CG83 [Accessed 01/05/2012].

Oeyen SG, Vandijck DM, Benoit DD, Annemans L, Decruyenaere JM. Quality of life after intensive care: a systematic review of the literature. Crit Care Med 2010;38(December (12)):2386-400.

Orwelius L, Nordlund A, Nordlund P, Simonsson E, Backman C, Samuelsson A, et al. Pre-existing disease: the most important factor for health related quality of life long-term after critical illness: a prospective, longitudinal, multicentre trial. Crit Care 2010;14(April (2)):R67.

Paul F, Rattray J. Short- and long-term impact of critical illness on relatives: literature review. J Adv Nurs 2008;62(3):276-92.

Peskett M, Gibb P. Developing and setting up a patient and relatives intensive care support group. Nurs Crit Care 2009;14(January-February (1)):4-10.

Samuelson KAM. Unpleasant and pleasant memories of intensive care in adult mechanically ventilated patients-findings from 250 interviews. Intensive Crit Care Nurs 2011;27(2): $76-84$.

Sigurgeirsdottir J, Halldorsdottir S. Existential struggle and selfreported needs of patients in rehabilitation. J Adv Nurs 2008;61(4):384-92.

Svedlund $M$, Axelsson I. Acute myocardial infarction in middleaged women: narrations from the patients and their partners during rehabilitation. Intensive Crit Care Nurs 2000;16(August (4)):256-65.

The Ministry of the Interior and Health: Health Care in Denmark. Available from: http://www.sum.dk/Aktuelt/Publikationer/ Publikationer/UK_Healthcare_in_DK.aspx [Accessed 01/05/2012].

Ulvik A, Kvale R, Wentzel-Larsen T, Flaatten H. Quality of life 2-7 years after major trauma. Acta Anaesthesiol Scand 2008;52(February (2)):195-201.

Van Pelt DC, Milbrandt EB, Qin L, Weissfeld LA, Rotondi AJ, Schulz $\mathrm{R}$, et al. Informal caregiver burden among survivors of prolonged mechanical ventilation. Am J Respir Crit Care Med 2007;175(January (2)):167-73.

Williams TA, Leslie GD, Brearley L, Dobb GJ. Healthcare utilisation among patients discharged from hospital after intensive care. Anaesth Intensive Care 2010;38(4):732-9. 